\title{
AC 2012-3732: ENGAGING ALL STUDENTS IN ENGINEERING
}

\section{Dr. Christine M. Cunningham, Museum of Science, Boston}

Christine Cunningham is a Vice President at the Museum of Science, Boston, where she oversees curricular materials development, teacher professional development, and research and evaluation efforts related to K-16 engineering and science learning and teaching. Her projects focus on making engineering and science more relevant, understandable, and accessible to everyone, especially marginalized populations such as women, underrepresented minorities, people from low socio-economic backgrounds, and people with disabilities. She is the Founder and Director of the Engineering is Elementary project.

\section{Ms. Cathy P. Lachapelle, Museum of Science, Boston}

Cathy Lachapelle currently leads the assessment efforts for the EiE curriculum, designing assessment instruments, pilot and field testing them, and conducting research on how children use the EiE materials. She has worked on a number of research and evaluation projects related to K-16 STEM education, including the Women's Experiences in College Engineering (WECE) study of factors influencing the persistence of undergraduate women in engineering schools. She is particularly interested in how students learn science, engineering, and mathematics through collaborative interaction and through scaffolded experiences engaging in disciplinary practices. Lachapelle received her B.S. in cognitive science from MIT, and her Ph.D. in psychological studies in education from Stanford University. 


\section{Engaging ALL Students in Engineering}

\section{INTRODUCTION}

The introduction of a "new" discipline — engineering — into K-12 education comes with both opportunities and responsibilities. One opportunity is that, as a new discipline for this age level, relatively few entrenched ways of operating currently exist; there is room to start fresh with an eye toward best practices. At the same time, engineering has a history at postsecondary levels in which certain groups have been traditionally marginalized or underrepresented in colleges, universities, and the workforce [1]. As we introduce engineering into K-12 education, we must work vigilantly to ensure from its inception that such patterns are not prevalent at this level.

Though little research has been done looking at young children's interest in engineering at an early age - exposure to engineering in elementary schools in the United States has been minimal at best-research on children's interest in and attitudes towards science is informative because engineering and science tend to be associated. Research has concluded that it is necessary to address disparities in access and exposure to science at an early age because students' interest in science tends to decline after elementary school [2-5]. Girls' attitudes towards science tend to be more negative than those of boys, and while the attitudes of both boys and girls tend to become more negative as they get older, girls' attitudes become even more negative relative to boys' [3, 5]; however this pattern does not hold for African American girls, who tend to have more positive attitudes than both African American boys and white girls [6]. Students from cultures and groups underrepresented in science, for example English language learners and students from high-poverty areas, may have more trouble than students from well-represented groups in navigating the differences between their home cultures and the culture of science: including differences in practices, expectations, norms of interaction, and the culture of school science. This may lead to difficulties with achievement even where interest exists [7, 8].

In 2003 we began development of a curriculum for elementary school-aged children that would introduce them to principles of engineering and technology: Engineering is Elementary (EiE). Grounding our work is a belief that individuals, engineering disciplines and solutions, and society benefit when all members engage in problem solving, innovation, inquiry, and engineering design. Our materials, therefore, would be designed to reach all children. Our team was and continues to be especially committed to attracting, reaching, and engaging underrepresented, underperforming, and underserved students including girls, minorities in STEM, students from low socioeconomic backgrounds, students with individualized education plans, and English language learners. From the project's inception, we generated design principles that would be maximally inclusive. We also ensured that the student data we collected included information about student demographics so we could parse our analyses to examine the effects of the curriculum on different populations.

An equitable and inclusive engineering curriculum must demonstrate the relevance of engineering to the real world. It must engage students in active participation in the practices of engineering as they work toward developmentally appropriate design challenges, with scaffolding and guidance to support students as they learn key concepts and practices and become fluent with the cultural norms of engineering. It must engender learning environments where students can contribute, collaborate, and develop their own sense of agency, expertise, and 
ownership. This call is similar to what others have advocated in science [2, 9]; however engineering education affords unique opportunities heretofore unrecognized.

Engineering is Elementary meets the five key criteria for project-based learning. Students (1) start with a problem they are challenged to solve; (2) explore the dimensions of the problem and possible solutions using guided inquiry; (3) work collaboratively to develop designs to solve the problem; (4) have their performance scaffolded in a variety of ways so they can engage in new practices and participate at a deeper level than if left to their own devices; and (5) produce designed, iteratively improved solutions and share them with the classroom community or others [10]. Like educators who have advocated for project-based learning [11], we view our efforts as contributing to student motivation and engagement, as well as to deeper learning of concepts and a broader learning of the practices, discourses, and culture of the discipline-in our case, of engineering. We argue here that these aspects of engineering through inquiry and project-based learning help set the stage for equity, by providing a richer environment with more frequent and varied opportunities for interaction, engagement, and learning.

There is much that curriculum design can do to foster equity in elementary engineering. Based on the literature and our experiences working in classrooms, we developed a set of 14 design principles for curricula and materials that guided the development of Engineering is Elementary. Here we articulate these principles, describe them, link them to relevant literature, and provide some examples of how they have influenced design decisions and classroom outcomes. This is not offered as a comprehensive list but rather as a starting place that should be continue to be discussed, researched, and revised.

\section{INCLUSIVE DESIGN PRINCIPLES}

\section{Set Learning in a Real-World Context}

Research has shown that "many students who are academically competent in the school subject matter ultimately view school's knowledge and skills as irrelevant for their future career and/or everyday lives” [9]. In order to increase the interest of students-particularly those who are underrepresented - in engineering and science as fields of study and as future career opportunities, students must see the relevance of what they are learning to the real world, and be able to see themselves filling such roles in the future world. The study of real-world contexts such as the local environment or global contexts has been found to increase students' engagement, enthusiasm, and achievement $[12,13]$. An emphasis on the social and societal connections with engineering and science-the place of engineering and science in development of knowledge and technology, the roles of engineers and scientists in driving theory-building and technological change, and the effects of these disciplines on all aspects of modern life-increases interest and motivation of students to drive their own learning and achievement [2].

In this section we introduce three design principles that contribute to greater interest and motivation for all students, but particularly groups who are underrepresented in engineering: (1) using narratives to develop and motivate students' understanding of the place of engineering in the world; (2) demonstrating how engineering helps people, animals, and/or society; and (3) introducing a variety of role models with diverse demographic characteristics. 
Use narratives to develop and motivate students' understanding of the place of engineering in the world. A narrative context helps students to understand the purposes, concepts, and processes of engineering, because narrative is humanity's natural means of learning and remembering [14]. Students connect to stories at a personal level [15]. Providing a coherent narrative that sets school learning into a larger, connected storyline context can engage students in seeking out and constructing their own understanding and provide a natural point of entry into the culture and aesthetic of a new discipline [16] such as engineering. Interest benefits all students, but can particularly boost the participation of girls and other underrepresented minorities who may be less predisposed to identify with or apply themselves to more technical studies or the physical sciences. A narrative can help to raise questions in students' minds, and arouse their curiosity and imagination [17]. The "so what" question is a perennial one in schools, particularly when science instruction is divorced from direct experience [18]. Helping students to connect school learning to the real world can motivate students by providing relevance for what they are learning, whether that is science or technological problems and problem-solving [18-20]. Narrative stories and controversies that address science and engineering as they apply to people's lives have the potential to powerfully affect students' attitudes towards and understanding of science, engineering, and technology and how they are practiced [21].

To help students situate their tasks in the real world, each EiE unit begins with a storybook that introduces a problem that a protagonist would like to solve. The problem is the same as or similar to the one that students will encounter in class. Anchoring students' activities in a setting and narrative helps them to situate what they are doing in a larger problem space. Students often evoke the storybook character or setting as they work on their solutions.

For example, in the second-grade class taught by Ms. Smith, students justified the criteria they chose for a good design by referring to the context set by the story. The students were working on choosing a site for a model Tarpul, a kind of gondola used to cross rivers in Nepal. In the story and context for the Evaluating a Landscape EiE unit, Suman is a boy who is concerned about the siting of a Tarpul near his home, because his grandmother is sometimes ill and needs to be transported across the river to the nearest clinic.

Ms. S: Who has tested site H? Go back to that page for a second. Look on your test page where you wrote how many weights you tested. All of you tested site H. Can you tell me how many weights you got [into the model Tarpul]? When you tested H? If I said to you, ten of those cubes equals one person, how many people could you put in your Tarpul to cross the river? Sam?

Sam: 26.

Ms. S: How many people would that be?

Sam: Two. Two and a little bit.

Ms. S: Let's be safe and call that two. We won't count the leftovers. Ellie? How many weights could you put in?

Ellie: 36 . That's like three people.

Ms. S: How about the rest of you? Jenny?

Jenny: We got 44 weights in. That's, um, 4 people.

PS: Jessica?

Jessica: We got 15 weights in the cup. (Ms. S: prompts) One person.

Observer: What would be the safest number? 
Alex: 2 people.

Ms. S: Why would 2 be the safest?

Ellie: Because if you were with your family you might need to be with someone else. Jenny: If someone can't move they can't pull themselves across.

Ellie: And if you're a little kid with your mother, or if you're sick, you need someone to help you get across.

In weighing criteria for their optimal Tarpul solutions, the children are able to draw upon the sick-grandparent scenario in the storybook to generate a solution that suggests at least two people should be accommodated by a safe design .

Demonstrate how engineers help people, animals, or society. Research finds that many students, particularly girls and underrepresented minorities, are interested in "helping" careers [19, 22, 23]. Students of both genders hold stereotypical views about physical science topics and activities as "for boys" and biological activities as "for girls" [22]; girls prefer and choose to participate more frequently in biological sciences than in physical science and engineering [2326]. Looking at college-bound high school students, Miller, Blessing and Schwartz [23] found that girls tended to choose people-oriented majors, and when choosing a science or engineering major, tended to focus on fields like biology which they saw as allowing them to help animals, or people, particularly through health professions. Girls want to see the relevance of science and other school subjects to their lives, or to see its social value [27]; girls' attitudes towards school subjects is affected by these perceptions of relevance [4].

However, the ways in which engineering benefits people, society, and the environment are not generally perceived by students. Engineering activities at the grade school level overwhelmingly tend to focus on the physical sciences: robot design is popular, as are challenges such as egg drops, vehicle races, and potato launchers. EiE units are specifically designed to counteract this trend. Each unit helps children to understand the societal impacts (both positive and negative) of engineering; the storybook and core design challenge of each EiE unit are carefully created and presented to draw out the ways in which the engineering solution contributes to people's lives.

For example, electrical engineering is not a field that has traditionally attracted large numbers of women. In EiE, instead of presenting circuit construction as a decontextualized exercise, children design electric circuits as part of a challenge focused on ensuring that baby lambs have enough water in their drinking trough. The circuit is one component of a larger alarm system students design to alert the lambs' caregiver when the water level is low. A motivational context that helps students to understand how their efforts might be used by and benefit someone (in this case both the caregiver and the lambs) can be very engaging for children.

Provide role models with a range of demographic characteristics. Girls perceive science as difficult, uninteresting, and leading to unattractive lifestyle [23, 27]. Girls receive mixed messages about careers and gender roles from the media; however positive role models can be influential [19]. A variety of role models — of both sexes from a variety of races and ethnicities, with different abilities/disabilities, and with a wide range of hobbies and interests-is necessary to combat these perceptions. 
In the introductory storybooks, EiE offers a range of engineer and scientist role models; each story features a child protagonist and an engineering mentor. The stories have been carefully planned to highlight a diverse group of people engineering. EiE sets the stories in countries around the globe so that the featured children are from a variety of races and ethnicities. Early on, EiE staff created a chart of attributes of each of the 20 characters with the goal of enabling readers to identify with at least one of them. For example, the male and female storybook children enjoy a variety of hobbies, have varied personalities, live in different family structures, and some have disabilities (a wheel-chair user, child who is blind, child with Down Syndrome, and child with a limb birth defect). The characters model that everyone can engineer.

In an EiE classroom it is not uncommon to hear a child saying that "[storybook character] looks like me" or expressing a preference about which protagonist is his or her favorite. Multiple teachers have reported that an immigrant child from India or the Dominican Republic became a star when the story was set in their birth country - teaching their interested classmates more about their native language or customs. Another teacher reported that their class had a long and sensitive discussion about Down Syndrome when they realized during whole-class reading time that one child in the class had a sibling with Down Syndrome. Another teacher related this story:

When I first started the unit, before the extra books arrived, I used Paulo's Parachute Mission as a read aloud and we had great discussions on many levels - from the problems Paulo faced... The kids loved this story and almost spoke as if Paulo was their own personal friend... it was really cool. (survey 4039)

\section{Present Design Challenges that are Authentic to Engineering Practice}

Research indicates that students learn concepts and skills through experience as they work and learn in rich contexts that mirror disciplinary problems and practices [28-30]. Children's learning is more profound when they engage in realistic disciplinary practices [31, 32] that include the social and epistemic practices of a discipline and put key concepts into productive use [33-36]. Recent research has shown that inquiry-based and project-based learning approaches in science leads to comparable or improved outcomes for students as compared to more traditional science [37-43].

Our next five design principles regarding authentic opportunities to practice engineering address students' need for agency and ownership, as well as their need to do work that is "real". These include (4) ensuring that design challenges are truly open-ended; (5) making evident the value of failure for learning and improving designs; (6) producing design challenges that can be evaluated with both quantitative and qualitative measures; (7) cultivating opportunities for collaboration and teamwork; (8) engaging children in active, hands-on, inquiry based engineering activities.

Ensure that design challenges are truly open-ended with more than one correct answer. All too often science lessons are presented as a task in which students' goal is to arrive at the correct answer. By mid elementary school, students readily categorize themselves as "good at school/science” or not, based upon their performance on these narrowly defined tasks and questions. 
For teachers, open-ended challenges can invite the use of new pedagogical strategies and ways of thinking about learning. For students, particularly those who have underperformed in the "correct" answer system, the openness of the problems and their solutions is refreshing and can re-engage their efforts. Open-ended activities invite deeper understanding, which can be particularly attractive to girls: research has shown that girls in particular strive for deep conceptual understanding and reject more formulaic, rote learning [44]. Open-ended questioning, inquiry, and problem-solving have also shown benefits for the achievement and attitudes of urban minority students, particularly African-American boys [45]. With open-ended activities, students can more readily make connections with their interests and prior experiences, and they have more reason to listen to and respect the views of others [46].

In the real world, engineering problems rarely have one unique solution-much depends on context and constraints. To communicate this feature of engineering to children; to foster creativity, problem solving, and innovative thinking; and to engage children who may have checked-out of rigid school activities that must result in one answer, EiE creates design challenges that afford a myriad of solutions. The challenges identify a set of criteria and constraints and the children evaluate their solutions related to how well they meet these. For example, in one lesson children are challenged to design a parachute that is "mission" ready. Students need to design parachutes that fall as slowly as possible, but that also can fit within a small space, as limited space is available on a spacecraft. These two criteria are in tension: larger parachutes tend to fall more slowly. Armed with results of experiments testing a variety of canopy materials, sizes, and suspension line lengths, teams plan, create, and test their ideas. They can see through class sharing that multiple ways of approaching and solving the problem are acceptable.

Value failure for what it teaches. Failure is a necessary and inherent part of engineering that invites subsequent improved designs. In addition to not converging to one "right" answer, we encourage children to "fail often to succeed sooner" [47]. Embracing failure as a necessary part of the engineering design process can be a new experience for students. Instead of "being wrong”, failure is cast as a critical part of the process from which all engineers learn.

EiE invites children to think about engineering problems as an iterative event-a solution can always be improved. Initial designs may "fail" to meet the baseline criteria set forth, but such failures enables students, like engineers, to learn more in order to make their subsequent designs better. The focus is one of constant improvement-EiE design challenges call for students to redesign their solutions at least once. A number of teachers have reported to us that students readily embrace the opportunity to continually hone their thinking and solutions, requesting the chance to continue to work to improve it before and after school, during recess, and over holidays. Teachers reported:

Several students kept bringing in play dough that they made at home. They wanted to improve until they perfected it. When they brought it in, many wanted to share the improvements they made and why they felt it was successful. — Grade 4 Teacher

I assigned an extra credit to try and improve the [play dough] recipe with further research at home. All 21 students participated! Parents communicated that the local super market was doing a booming business with packages of flour! — Grade 3 Teacher 
The majority of my students have continued to test materials and build parachutes during their free time (recess!) — Grade 3 Teacher

Furthermore, engineers often test their designs to the limit-probing the edge of where they function so they understand under what conditions they will function. Testing a design to failure can be fun for students, and highly engaging. One teacher commented, "When we tested our earthquake models, the kids were delighted to be able to shake the daylights out of the structures and they were amazed that they remained intact.”

That the productive use of failure is a crucial aspect of engineering can be liberating for many students - especially low-achieving students [48]. Instead of worrying about being wrong or appearing stupid, students' attempts are woven into an iterative process that aims to create a feasible solution. The iterative part of the engineering design process asks students to keep analyzing their tests to determine how they might improve their solution a bit more in the next design. A student doesn't fail; a particular design fails and in so doing hopefully sparks a set of new, improved ideas.

Produce design challenges that can be evaluated with both qualitative and quantitative measures. The possibility for multiple solutions does not mean that all of them meet or address criteria equally as well. Children (and adults) often champion their own ideas, without adequately considering designs of others or without conducting “objective” analyses.

To encourage students to analyze their various solutions objectively and determine which best meets the challenge's criteria, EiE design challenges aim to have students collect both qualitative and quantitative data during testing. Materials ask students to reflect upon the needs of the design and assess how well each solution meets it. Thus, instead of children's preconceptions, popularity, or perceived "smartness" driving decisions, more objective and impartial data are available to be considered.

EiE strives for quantifiable tests: presenting results as a number allows for a clear measure for comparison. However, quantification can prove difficult, especially using only the tools and instruments available in elementary schools. In some cases, EiE metrics ask students to rate each of a series of variables against a rubric with a numbered scale. The sum of the numbers generated by their observations provides a "quantitative" measure. In other challenges, quantification is linked more closely to a single test. For example, to test children's wall mortar strength, a wrecking ball (a golf ball) on a string is used. The children pull the ball back 10 degrees and let it drop, then repeat with progressively larger angles. They record at what angle their wall is destroyed.

Whether measures are quantitative or qualitative, they must be sensibly linked to the goals and context of the design challenge. Ultimately, though most EiE units provide quantitative and qualitative measures that students can use, the goal is for students to be able to identify what a successful design should be able to do and then develop and improve their own measures. In a few EiE units, students develop rubrics for measurement on their own by thinking carefully about what the desired outcomes of their technology would be and how they might measure these. For example, in the Designing a Play Dough Process unit, children develop a rubric to 
measure the quality of play dough, while in Designing Plant Packages they develop a rubric to measure plant health.

In the excerpt from the second-grade class discussed earlier, students reasoned about the weight their Tarpuls could carry both quantitatively (how many weights) and qualitatively (whether this was sufficient for a viable design). The focus of the discussion was on the performance of designs and how the measurement of weight carried could be used to evaluate it.

Cultivate collaboration and teamwork. Competitive environments that nurture the designation of a "winner" can differentially curtail or discourage participation of some groups, especially girls and underserved minorities [27]. Many girls and some American minority cultures value interaction and collaboration more highly than competition $[8,19]$. With collaboration a highly valued skill in both science and engineering, and elementary educators tasked with developing in their young charges the ability to work productively in groups, it makes sense to engage all students in practicing these skills.

Collaboration and teamwork afford students rich opportunities to develop expertise and identity as valued science and engineering contributors. Learning environments where such interactions are the norm allow students to be valued as contributors in a variety of ways, reducing the disparate impacts of race and socio-economic status by allowing students multiple routes to gain social status instead of sorting and alienating them through hierarchies and competition [9, 49].

EiE lessons and tasks are designed to foster collaboration and teamwork within and among groups. In almost every activity children are working either with a partner or with a larger group. Care is taken not to compare or rank order groups' solutions and ideas against each other, but rather the challenges ask each group to compare their solution to a set of fixed design criteria as well as to prior designs the group has generated.

EiE teachers frequently mention learning to work in teams or teamwork as an important skill that is developed in and essential to EiE lessons. For example, one teacher remarked,

Three students, one from Jamaica, one from Sri Lanka and the third, a Bosnian, who never do anything together, were teamed up for this project. I marveled at their willingness to accept and test each others ideas and analysis without conflict. Their need to test their work and "save their frog" really helped to focus their efforts in a very positive way. To observe them working was a delight, the different perspectives each brought to the task were blended to engineer a very successful membrane. -Grade 5 teacher

Engage students in active, hands-on, inquiry-based engineering. Not surprisingly, children prefer to engage in hands-on activities and experiments in science rather than more traditional textbased activities; however, such learning experiences are still uncommon [2]. Not all hands-on experiences have an impact on student achievement [50]; however inquiry-based instruction that emphasizes active student engagement in analyzing and making sense of data is clearly superior to techniques emphasizing passive student learning when it comes to increasing student conceptual understanding [51] and inquiry ability (Cuevas 2005). A variety of studies have shown that girls in particular benefit from hands-on or inquiry-based learning [2, 52, 53] as well as African-American students, particularly boys [45]. Similarly, research has shown that inquiry- 
based instruction, unlike traditionally delivered science instruction, equally benefits boys and girls [54] as well as students from non-majority ethnic and/or socioeconomic groups [38, 43, 54, 55] and students with limited proficiency in English [54]. One study found that middle-school students working on an engineering design curriculum outperformed students using a traditional curriculum and students engaged in an inquiry-science unit on an assessment of science reasoning [56].

EiE is rooted in a belief that children should engineer, because hands-on work promotes engagement, interest, and learning. As one second grade teacher explained, "Our class was thoroughly engaged [in the submersible design challenge]. We even discussed using dental floss to tie to the submersible and pull it up... So many changes over time, inductive, deductive reasoning...”

\section{Scaffold Student Work}

Students need guidance in order to learn complex processes and to achieve and transfer what they have learned to new problems (Mayer, 2004). Instructional methods that provide guidance to students who are learning actively have consistently been shown to be superior to pure "discovery" methods in which students do not receive guidance (Hmelo-Silver etal 2007; Mayer 2004). Scaffolds can include modeling and coaching to make the practices and ways of thinking of a discipline explicit, providing expert hints and explanations, and providing structures and prompts to support students engaging in complex tasks in order to reduce cognitive load (HmeloSilver et al 2007).

Three design principles address scaffolding directly. These include (9) modeling and making explicit the practices of engineering; (10) assuming no previous familiarity with materials, tasks, or terminology; and (11) producing activities and lessons that are flexible to the needs and abilities of different kinds of learners.

Model and make explicit the practices of engineering. There are many disciplinary practices and heuristics specific to engineering. For example, the work of engineers as they solve a problem can be generalized into a series of steps called the engineering design process. Similar to the scientific method, this sequence is not absolute or linear; rather it is a tool that can guide the work of designers.

Tackling an open-ended problem can be daunting for students. Engineering problem-solving is a complex process that can tax their abilities. Scaffolding by making the engineering design process explicit and by supporting each step with questions and prompts can increase students' success and achievement. Parsing the problem into smaller steps with discrete goals can help to focus children's efforts. During engineering design, novices are often in a hurry to build and test their ideas, bypassing the brainstorming and planning phases that are often critical to creating a successful design.

While few young students may have had exposure to the norms and practices of engineering, there may be a particular need to provide support for students from backgrounds whose cultural or home norms might not mirror those of Western science, whether they are from ethnic subgroups, language minorities, or high poverty areas. Teachers can call attention to the practices 
and values of engineering by explicitly naming the steps and saying why and when engineering practices and values are important, making the contrasts apparent to students in a context that does not devalue the practices they are accustomed to at home or elsewhere (Lee, 2003).

EiE promotes a simple five-step cyclical process for engineering design. Though many standards for high school or middle school use a 7-step or 10-step engineering design process, elementary teachers' insistence that five steps was the maximum number that their young charges would remember led us to develop a less nuanced (though functionally similar) process for younger students. In the context of a design goal, children (1) ask questions, (2) "imagine” or brainstorm a variety of possible solutions, (3) choose one design to plan, then (4) create and test a design based on their plan, and (5) analyze and decide how to improve the design. To aid both teachers and children, each step is accompanied by a series of questions and prompts designed to focus children's thinking. Teacher materials emphasize that the process is not formulaic and rigid but rather is meant as a guide. It can begin with any step, and steps need not be followed in order.

This is similar to inquiry-based instructional units described by Cuevas (2005), where students also focus on an "inquiry framework" with five areas: questioning, planning, implementing, concluding, and reporting. For teachers, Cuevas specified a matrix of different methods of scaffolding appropriate for different levels of student prior experience and skill with conducting inquiry. Mirroring our own experience, Cuevas reports that use of an explicit framework and gradual removal of teacher guidance encouraged students to take more initiative and responsibility over time.

Students benefit from the explicit discussion and modeling of other engineering practices as well: for example, the construction of circuit diagrams in electrical engineering, as in Ms. King's fifth grade class.

Ms. K: What's the difference between the picture of the wire and the diagram of the wire? Leslie: One is squiggly, the other is straight.

Ms. K: That's right; in diagrams the wires are always straight, even though they're not in the real world. So, what symbols do we need to make the classroom diagram?

Jared: A battery.

Ms. K: Come up and get the symbol and put it on the board for us. What else do we need?

Cate: A bulb. (Cate posts the symbol on the board next to the battery.)

Ms. K: if the wires need to be straight, then what will the corners look like?

Tina: Right angles.

Peter: Could it be a triangle?

Ms. K: Do you mean like this? (Ms. K draws a triangle-shaped circuit with parts in it.) It will never be that way. Why do you think so?

Tom: So people don't wonder why it's that way.

Ms. K: (Draws a square circuit.) It always has perpendicular lines. Now if I put a bulb here, a battery here, Tina would you draw the wires?

(Tina draws another square connecting to the first.)

Ms. K: Alright, I'm going to have you practice doing schematic diagrams now.

Brian: Could you have something perpendicular in a different shape?

Ms. K: Draw what you mean on the board, in a different color chalk.

(Brian draws a circuit in an L-shape.) 
Ms. K: I guess - I think-I don't think it's wrong, but you want it in the most clear way, like when you do fractions you want the simplest fraction. I'll give you papers now with a picture of a circuit at the top. Use the symbols and draw a schematic diagram.

In this excerpt, Ms. King works with her students to establish the "ground rules" for making a circuit diagram, including the rule-of-thumb that it should be laid out in the "most clear" way. Circuit diagramming is a form of discourse practice in electrical engineering, and Ms. King's guided discussion makes explicit the rules of this practice, a form of scaffolding that Nasir, Rosebery, Warren, and Lee [57] call "making visible the structure of a domain" and that Aikenhead [7] calls the teacher's support of “cultural border crossing”. When we recognize that learning is a cultural process (not only a cognitive process) for all students [57] and that all students need help to become comfortable with the culture of engineering, including its norms and practices, we are able to design learning environments that welcome everyone, without running the risk of excluding those students' whose personal cultural worlds are most discordant with that of engineering.

Assume no previous familiarity with materials, tasks, or terminology. Children enter schools with a wide range of experiences and backgrounds that can affect their achievement in school [8]. In an effort to minimize the effects of prior exposure and experiences on children's success with EiE tasks, lessons introduce children to the materials and terminology and incorporate activities that give children relevant experience with them before they need to use such knowledge in tasks. Such introductions and interactions allow children who are English language learners or children who have not encountered the materials before to engage on a more level playing field. For example, the project does not assume that children know what a pom-pom is or what the differences might be between index cards, “regular” printer paper, and wax paper. To help build familiarity, each EiE unit contains one lesson designed to give children time to interact with the materials, label them with their names, and explore their properties. Teachers have remarked that incorporating such explorations helps children who may come from more disadvantaged backgrounds as well as English language learners. In the following excerpt, Ms. Glick prompts her fourth graders to use varied vocabulary as they explore properties of their material.

Ms. G: Give me some words to describe your play dough.

Jan: Soft.

Child: Sticky.

Joey: Little pieces that are not squishy.

Ms. G: The salt is in there.

Gina: Grains.

Ms. G: Here's a big word-pliable.

Joey: You can change its shape.

Gina: Movable.

EiE activities are also designed to afford students experiences using a variety of measurement tools such as rulers, measuring cups, and weights. They practice mixing, cutting, taping, and other construction skills. One teacher reported that "the kids became experts at measuring, leveling, mixing etc. They enjoyed all parts of this lesson. It felt more like playing than science. The whole engineering process fit in with our attempts to make a better play dough.” Elementary Science Specialist 
Produce activities and lessons that are flexible to the needs and abilities of different kinds of learners. The developmental and cognitive abilities of children in elementary classrooms can differ greatly. Offering challenges that can be successfully accomplished by a range of students requires that materials can be scaled up or down. Fortunately, engineering challenges are well suited for differentiated learning. Once a basic challenge has been developed, it can be made increasingly complex by adding additional criteria and constraints.

EiE units are all developed at two levels-basic and advanced. The basic materials are geared toward children in grades 1 and 2 and contain less reading and writing and more pictures than the advanced materials, which are developed for grades 3-5. Additional and more complicated criteria, constraints, and measures for the design challenges are also introduced in the advanced materials. Within both basic and advanced are additional tips for simplifying or expanding the activities as well as tips for scaffolding English language learners. Teachers can choose the materials that meet the needs of their students.

Many elementary classrooms contain students with a wide range of abilities; differentiated learning and instruction is common. For example, one very skilled kindergarten teacher recounted:

This year I had three children with physician diagnosed ADHD. The entire year, they were constantly out of their seats moving around every 5-10 minutes. Until we started our EiE unit. I was shocked to observe that while they were engaged in the engineering challenges, all of them were focused and on-task for up to 40 minute stretches. Furthermore, although ADHD children often have a difficult time with the writing process, both motorically and organizationally, I saw a huge investment and attention to task and detail with the writing components embedded in EiE in a way that I hadn't all year from those students. It was remarkable! I think the combination of allowing the children to manipulate materials, to engage with them at their own level, to make cross-curricular connections, and to work on a challenge with a goal of finding a solution by trying again and again reached these students as nothing else that year had. - Kindergarten Teacher

The class I worked with is by definition a co-taught classroom. Students are placed in the room based on their IEP's. Some are role models. Some children have behavioral challenges. But - these [EiE] lessons really kept them focused and engaged. They really anticipated each next step and I feel like it was an outlet for their energy_-even reading the stories. Because the unit is activity based, it is a great tool. - Elementary Science Specialist

\section{Demonstrate that "Everyone Engineers" and Everyone CAN Engineer}

Children can enjoy "doing science" without having any desire to "be a scientist"—a child's identity is shaped by where they come from both in place and in culture-but also by their own desires about what they want to do and become, as a person who has an effect on the world [58]. Whether a child wishes to be an engineer or not, we know that students are more engaged, interested, and confident when they have both the responsibility and the opportunity to become more competent and to make choices about what forms of competence they wish to "specialize" in. Students benefit when they are engaged in working collaboratively, not competitively, when students have choices for how to show their competencies, and when they are evaluated based on their effort. 
Our final three design principles focus on enabling and supporting the development of student identities as engineers, or at least as students who are good at engineering or understand the value of engineering. These include (12) cultivating learning environments in which all students' ideas and contributions have value; (13) fostering children's agency as engineers; and (14) developing challenges that require low-cost, readily available materials.

Cultivate learning environments in which all students' ideas and contributions have value. When competence is something ascribed to particular individuals, students with lower achievement on standardized measures have less motivation to contribute and participate. However, environments where students can gain social capital through their participation and where students' contributions are valued, are more likely to engage students. For example, Roth and Lee [59] reported that a low-achieving student with learning disabilities became an "expert" when given the opportunity to engage in meaningful practices of environmental science; minority aboriginal students in the same project showed much higher levels of engagement when allowed to choose their mode of participation [60].

Such environments, where students are not compared on tasks but instead are valued for their contributions, are less likely to reinforce socioeconomic inequalities and ethnic and cultural differences and more likely to promote broad engagement [49,61]. An equitable classroom is one where all students can negotiate and expand the roles they play, where all students share authority, where students are agents with ownership over their learning, and where all students have the opportunity and the responsibility to participate with competence [9].

To afford opportunities for equitable productive engagement for all students, the curriculum they engage in must offer a range of means and opportunities for social and cognitive interaction. EiE provides such opportunities through the careful design of engineering challenges as well as through the structuring of participation in engineering design process routines. Engineering challenges are designed to have many possible solutions, with competing criteria for success. For example, one group of students may produce a water filter that works quickly, while another produces one that is slower but removes more contaminants. Students conduct experiments to learn about the performance of different materials or procedures, and then decide as a group their strategy for applying what they have learned to a design. At the same time, EiE materials include routines for participation that encourage all students to take responsibility for contributing to the group: for example, students brainstorm individually before sharing their ideas with their group and discussing the options set forth. The combination of complex challenges and a variety of participation structures allows students a myriad opportunities for engaging, contributing, and sharing authority and expertise in the classroom. Reflecting on their experiences, teachers noted:

As the teacher I got to observe over 90 students being engineers. The best thing for me was how well students got along with other students that they would not usually work with. I saw new friendships build as they worked in teams to make their parachutes. As problems came up, the teams learned that they had to work them out with each other using nice words. Some of the lower students became the leaders of the group when it was hands-on time. Grade 3 Teacher

It was amazing watching the groups argue, then work cooperatively [to build submersibles]....This class not only learned the concepts of mass, volume, and density but 
also were able to apply knowledge into functional learning. They all want to become ocean engineers! —Grade 2 Teacher

The lessons promoted more out-of-the-box thinking. Students were more flexible in their thinking and found multiple ways to solve a problem. This encouraged more collaboration among students. We found students to be more open to other group members' ideas. It helped promote a positive attitude regarding engineering. — Grade 5 Teacher

Foster children's agency as engineers. Equity is not only an issue of opportunity to learn and participate; an equitable classroom is also one in which all children can see the relevance of what they are learning to their own lives. Students must be able to develop their identities as people who can do engineering, and who are capable and interested in engineering. Culture, gender, and socio-economic status all play into students' views of themselves, as well as what it means to be "science people" in school [9]. Whether they are knowledgeable or struggling, students are more likely to adopt a science (or engineering) identity if they have the opportunity to be active and collaborative producers of knowledge for the classroom community. If identities available to students are limited to attributes of individuals such as "good at tests and worksheets" and "good reader”, then students (particularly struggling students) are more likely to opt out.

EiE units deliberately cast students as engineers. The language used throughout the lessons invites students to engineer solutions to problems. Children quickly internalize their roles as engineers, excitedly proclaiming "We are going to be mechanical engineers today!" or asking "When do we get to engineer again?"

They enjoyed working together to design then build their project. They found out they can be engineers and solve problems. -Grade 4 Teacher

Students loved being engineers! Engagement totally helped increase knowledge of rocks and minerals. - Grade 4 Teacher

They learned they can be/are engineers. They respected each other more clearly as "more able engineers". —-Grade 3 Teacher

When students feel they have room for agency in their own learning, they are more likely to take initiative. One EiE teacher reported that, after participating in Designing Windmills, two of her students "tracked down the opportunity to visit and tour a [wind] turbine," and one built a model wind turbine. Another teacher told us, "My students really liked the "power" of the decisions they had with this unit. They liked deciding in their groups how they wanted to try something rather than me telling them what to do!”

Develop challenges that require low-cost, readily available materials. In creating engineering design challenges, the EiE project has consciously worked to use low-cost materials that can be purchased at grocery or hardware store. There are a number of reasons for this. First, "everyday", inexpensive materials help children and teachers perceive engineering as accessible. Second, cash-strapped schools often have limited funds for materials. Third, by using inexpensive materials that can be purchased in neighborhood stores, children who are engaged by the challenges in schools have the opportunity to continue their explorations out of school. 
In fact, a number of teachers including those of urban, at-risk youth report that their pupils are so captivated by the challenge of improving their design that they secure materials and continue to hone their solutions at home after school or during vacations. For example, one teacher who completed the Designing Windmills unit was impressed that two of her students redesigned their windmill blades at home, resulting in significant improvements in power. A second reported that her students bought out all the flour at the local urban corner food mart over spring break as the class itself had decided to continue improving their play dough design at home during their vacation. A third teacher recounted the following two vignettes during two different years using $\mathrm{EiE}$; her comments reflect many of the attributes described above:

While working as a fourth-grade teacher, my bilingual Spanish-English class was working on the Environmental Engineering unit, designing water filters to remove tea, soil, and cornstarch from water. One member of this class was a tall, rather awkward child of African descent from the Dominican Republic. She seemed to lack confidence in herself and had never really fully engaged in many academic activities. When we began working on water filtration, she commented that this was a big problem in her home country, and she worked well with her classmates to clean the water during the course of the design challenge. At the end of the unit she asked to be able to take home a copy of all of her group's designs to look at in her home. I thought nothing of it and gave her the papers. Several months after we completed the challenge, she came into class, and said, "Señora N., lo hice, I did it!” I asked, "What have you done?” The girl responded, "I made a filter that gets the water perfectly clear. Could I stay after school some day and show you my designs?” (I should note that it is really difficult to remove all tea color from water.) This child had returned home, and because she could readily find the materials for the design challenge (she literally cut up old T-shirts and towels for some materials), had continued to work on designing her filter for months! I let her show the class her final design. I discussed her interest with her mother, a very supportive woman with a limited formal education but a desire to see her daughter triumph in this country. Shortly after talking with her mother, my student came in and told me, "For my next challenge my mother has arranged that when I return to the Dominican Republic this summer I am going to visit a man at a water treatment plant who is working on the desalinization of ocean water for drinking water.” The EiE challenge had piqued this child's interest and she connected it with a problem she knew affected her family's homeland. This child is now in the gifted and talented program and continues to thrive in math and science at the high school.

Last year, I worked with a very challenging student population; many of my students had been exposed to trauma and lacked of trust in adults and each other. This was often manifested through a lack of motivation on school assignments as well as outbursts of anger and defiance. Nevertheless, that all changed when my class began working on the Engineering is Elementary chemical engineering unit in which students design a process to make play dough. As we continued work in the unit, my students became so motivated that almost half of the class brought in play dough samples and processes that they had developed at home to try to improve the processes they were working on in class. During class, they would discuss the quality of their samples and try to figure out ways to combine their ideas to come up with the best possible sample. I had to extend the unit for several extra days to give them more design time, as they begged me for "more engineering time". We had a comparison of using wheat flour versus corn flour in our samples, as many of my Mexican and Central American students had access to corn flour at home rather than wheat, 
which brought in a cultural dimension to the activities that gave them pride in their identities. By using only materials that even my students of most limited resources had at home, the unit made the concepts accessible to all students. Several students ended the unit saying that they wanted to become engineers as adults, because that was something that they knew that they had the ability to do. — Grade 4 Teacher

\section{RECOMMENDATIONS}

The Engineering is Elementary project is firmly committed to creating curricular materials that invite all children to engage in problem-solving, inquiry, and innovation. Drawing from related research and our experiences, we articulated design principles and applied these principles to the guide the development of 20 elementary curriculum units. These units have been tested and used in classrooms across the country; to date we estimate that over 2,700,000 children and 33,000 teachers have used EiE. Research and evaluation data suggest that the EiE materials have engaged girls, children of color, children from low socioeconomic groups, and children with disabilities and have resulted in learning gains related to both engineering and science [62, 63].

We purport that attention to including underserved and underperforming groups must be central to the design of materials from their inception. Well-designed materials are critical for attracting, engaging, and retaining students' interest and confidence in engineering. Thus, we set forth our inclusive principles as a starting point for a conversation about resource design.

Set Learning in a Real-World Context:

- Use narratives to develop and motivate students' understanding of the place of engineering in the world.

- Demonstrate how engineers help people, animals, or society.

- Provide role models with a range of demographic characteristics.

Present Design Challenges that are Authentic to Engineering Practice:

- Ensure that design challenges are truly open-ended with more than one correct answer.

- Value failure for what it teaches.

- Produce design challenges that can be evaluated with both qualitative and quantitative measures.

- Cultivate collaboration and teamwork.

- Engage students in active, hands-on, inquiry-based engineering

Scaffold Student Work:

- Model and make explicit the practices of engineering.

- Assume no previous familiarity with materials, tasks, or terminology.

- Produce materials that are flexible to the needs and abilities of different kinds of learners.

Demonstrate that "Everyone Engineers" and Everyone CAN Engineer:

- Cultivate learning environments in which all students' ideas and contributions have value.

- Foster children's agency as engineers.

- Develop challenges that require low-cost, readily available materials.

We encourage others involved in K-12 engineering programming and resource development to carefully consider how they will actively reach out to underrepresented populations-for unless such concerns are at the fore, the status quo will continue. We welcome application, adoption, 
and modification of our principles by others. Our experience has taught us that we will continue to revise and refine these as we learn more.

Obviously, more research is needed both about elementary-level engineering and about how to develop materials that engage all students (in engineering). The opportunity for and magnitude of the impact of our EiE materials on a very wide range of students has far exceeded our initial expectations. Going forward, EiE plans to conduct research that measures the impact of the curricular design principles on students and to investigate in more depth the impact of the EiE curriculum on underserved groups.

\section{REFERENCES/BIBLIOGRAPHY}

1. Burke, R.J. and M.C. Mattis, eds. Women and minorities in science, technology, engineering and mathematics: Upping the numbers. 2007, Edward Elgar Publishing: Northampton, MA.

2. Brotman, J.S. and F.M. Moore, Girls and science: A review of four themes in the science education literature. Journal of Research in Science Teaching, 2008. 45(9): p. 971-1002.

3. $\quad$ Catsambis, S., Gender, race, ethnicity, and science education in the middle grades. Journal of Research in Science Teaching, 1995. 32(3): p. 243-257.

4. Clewell, B.C. and J. Braddock, Influences on minority participation in mathematics, science, and engineering, in Access denied: Race, ethnicity, and the scientific enterprise, G. Campbell Jr, R. Denes, and C. Morrison, Editors. 2000, Oxford University Press: New York. p. 89-137.

5. $\quad$ Reid, N. and E.A. Skryabina, Gender and physics. International journal of science education, 2003. 25(4): p. 509 - 536.

6. Hanson, S., Swimming against the tide: African American girls and science education. 2009, Philadelphia: Temple University Press.

7. Aikenhead, G.S. and O.J. Jegede, Cross-cultural science education: A cognitive explanation of a cultural phenomenon. Journal of Research in Science Teaching, 1999. 36(3): p. 269-287.

8. Lee, O., Equity for linguistically and culturally diverse students in science education: A research agenda. Teachers College Record, 2003. 105(3): p. 465-489.

9. Carlone, H.B., J. Haun-Frank, and A. Webb, Assessing equity beyond knowledge- and skills-based outcomes: A comparative ethnography of two fourth-grade reform-based science classrooms. Journal of Research in Science Teaching, 2011: p. n/a-n/a.

10. Blumenfeld, P., et al., Motivating Project-Based Learning: Sustaining the Doing, Supporting the Learning. Educational Psychologist, 1991. 26(3): p. 398, 369-398, 369.

11. Krajcik, J. and P. Blumenfeld, Project-based learning, in The Cambridge handbook of the learning sciences, R.K. Sawyer, Editor. 2006, Cambridge University Press: New York. p. 317-334.

12. Kang, H. and M.A. Lundeberg, Participation in science practices while working in a multimedia case-based environment. Journal of Research in Science Teaching, 2010. 47(9): p. 1116-1136.

13. Lieberman, G.A. and L.L. Hoody, Closing the Achievement Gap: Using the Environment as an Integrating Context for Learning. Results of a Nationwide Study. 1998.

14. Wilson, E.O., The Power of Story. American Educator, 2002. 26(1): p. 8-11.

15. Stinner, A., Providing a contextual base and a theoretical structure to guide the teaching of science from early years to senior years. Science \& Education, 1996. 5(3): p. 247-266.

16. Martin, B.E. and W. Brouwer, The sharing of personal science and the narrative element in science education. Science Education, 1991. 75(6): p. 707-722.

17. Klassen, S., The construction and analysis of a science story: A proposed methodology. Science \& Education, 2009. 18(3): p. 401423.

18. Buxton, C.A., Social Problem Solving Through Science: An Approach to Critical, Place-Based, Science Teaching and Learning. Equity \& Excellence in Education, 2010. 43(1): p. 120 - 135.

19. Baker, D. and R. Leary, Letting girls speak out about science. Journal of Research in Science Teaching, 1995. 32(1): p. 3-27. 
Klassen, S., The application of historical narrative in science learning: the atlantic cable story. Science \& Education, 2007. 16(3): p. 335-352.

21. Koul, R. and T.M. Dana, Contextualized science for teaching science and technology. Interchange, 1997. 28(2): p. $121-144$.

22. Jones, M.G., A. Howe, and M.J. Rua, Gender differences in students' experiences, interests, and attitudes toward science and scientists. Science Education, 2000. 84(2): p. 180-192.

23. Miller, P.H., J.S. Blessing, and S. Schwartz, Gender Differences in High-school Students' Views about Science. International journal of science education, 2006. 28(4): p. 363 - 381.

24. Buccheri, G., N.A. Gurber, and C. Bruhwiler, The Impact of Gender on Interest in Science Topics and the Choice of Scientific and Technical Vocations. International journal of science education, 2011. 33: p. 159-178.

25. Dawson, C., Upper primary boys' and girls' interests in science: have they changed since 1980? International journal of science education, 2000. 22(6): p. 557 - 570.

26. Drechsel, B., C. Carstensen, and M. Prenzel, The Role of Content and Context in PISA Interest Scales: A study of the embedded interest items in the PISA 2006 science assessment. International journal of science education, 2011. 33(1): p. 73-95.

27. Burke, R.J., Women and minorities in STEM: A primer, in Women and Minorities in Science, Technology, Engineering and Mathematics, R.J. Burke and M.C. Mattis, Editors. 2007, Edward Elgar Publishing: Northampton, MA. p. 3-27. Bruner, J.S., A short history of psychological theories of learning. Daedalus, 2004. 133(1): p. 13-20. University Press. 138 p.

30. Rogoff, B., Apprenticeship in thinking: Cognitive development in social context. 1990, New York, NY: Oxford University Press. 242.

31. Roth, W.-M., Experimenting in a Constructivist High-School Physics Laboratory. Journal of Research in Science Teaching, 1994. 31(2): p. 197-223.

32. Sawyer, R.K., The Cambridge handbook of the learning sciences. 2006, Cambridge, UK: Cambridge University Press.

33. Duschl, R.A., Science education in three-part harmony: Balancing conceptual, epistemic, and social learning goals. Review Of Research In Education, 2008. 32(1): p. 268-291.

34. Duschl, R.A. and R.E. Grandy, Teaching scientific inquiry: Recommendations for research and implementation. 2008, Rotterdam, The Netherlands: Sense Publishers.

35. Engle, R.A. and F.R. Conant, Guiding principles for fostering productive disciplinary engagement: Explaining an emergent argument in a community of learners classroom. Cognition and Instruction, 2002. 20: p. 399-483.

36. Rosebery, A.S., B. Warren, and F.R. Conant, Appropriating scientific discourse: Findings from language minority classrooms. Journal of the Learning Sciences, 1992. 2(1): p. 61-94.

37. Anderson, R., Reforming science teaching: What research says about inquiry. Journal of Science Teacher Education, 2002. 13(1): p. $1-12$.

38. Blanchard, M.R., et al., Is Inquiry Possible in Light of Accountability? A Quantitative Comparison of the Relative Effectiveness of Guided Inquiry and Traditional Verification Laboratory Instruction. Science Education, 2010. 94(4): p. 577-616.

39. Geier, R., et al., Standardized test outcomes for students engaged in inquiry based science curricula in the context of urban reform. Journal of Research in Science Teaching, 2008. 45(8): p. 922-939.

40. Kuhn, D., Reasoning about multiple variables: Control of variables is not the only challenge. Science Education, 2007. 91(5): p. 710726.

41. Lehrer, R. and L. Schauble, Investigating real data in the classroom: Expanding children's understanding of math and science. 2002: Teachers College Press New York.

42. Prince, M. and R. Felder, Inductive teaching and learning methods: Definitions, comparisons, and research bases. Journal of Engineering Education, 2006. 95: p. 123-138.

43. Wilson, C.D., et al., The relative effects and equity of inquiry-based and commonplace science teaching on students' knowledge, reasoning, and argumentation. Journal of Research in Science Teaching, 2010. 47(3): p. 276-301.

44. Zohar, A., Connected Knowledge in Science and Mathematics Education. International journal of science education, 2006. 28(13): p. 21.

45. Kahle, J.B., J. Meece, and K. Scantlebury, Urban African-American middle school science students: Does standards-based teaching make a difference? Journal of Research in Science Teaching, 2000. 37(9): p. 1019-1041.

46. Järvinen, E.-M. and J. Twyford, The Influences of Socio-cultural Interaction upon Children's Thinking and Actions in Prescribed and Open-Ended Problem Solving Situations (An Investigation Involving Design and Technology Lessons in English and Finnish Primary Schools). International Journal of Technology and Design Education, 2000. 10(1): p. 21-41.

47. Nightline, The deep dive: five days at IDEO, in Nightline with Ted Koppell. 1999, ABC News. p. 21:46.

48. Meece, J.L. and M.G. Jones, Gender differences in motivation and strategy use in science: Are girls rote learners? Journal of Research in Science Teaching, 1996. 33(4): p. 393-406. 
49. Olitsky, S., et al., Coherence, contradiction, and the development of school science identities. Journal of Research in Science Teaching, 2010. 47(10): p. 1209-1228.

50. Kirschner, P.A., J. Sweller, and R.E. Clark, Why minimal guidance during instruction does not work: An analysis of the failure of constructivist, discovery, problem-based, experiential, and inquiry-based teaching. Educational Psychologist, 2006. 41(2): p. 75-86.

51. Minner, D.D., A.J. Levy, and J. Century, Inquiry-based science instruction-what is it and does it matter? Results from a research synthesis years 1984 to 2002. Journal of Research in Science Teaching, 2010. 47(4): p. 474-496.

52. Burkam, D.T., V.E. Lee, and B.A. Smerdon, Gender and science learning early in high school: Subject matter and laboratory experiences. American Educational Research Journal, 1997. 34(2): p. 297.

53. Cavallo, A.M.L. and T.A. Laubach, Students' science perceptions and enrollment decisions in differing learning cycle classrooms. Journal of Research in Science Teaching, 2001. 38(9): p. 1029-1062.

54. Cuevas, P., et al., Improving science inquiry with elementary students of diverse backgrounds. Journal of Research in Science Teaching, 2005. 42(3): p. 337-357.

55. Thadani, V., et al., The Possibilities and Limitations of Curriculum-Based Science Inquiry Interventions for Challenging the "Pedagogy of Poverty". Equity \& Excellence in Education, 2010. 43(1): p. 21 - 37.

56. Silk, E.M., C.D. Schunn, and M. Strand Cary, The impact of an engineering design curriculum on science reasoning in an urban setting. Journal of Science Education and Technology, 2009. 18(3): p. 209-223.

57. Nasir, N.i.S., et al., Learning as a cultural process: achieving equity through diversity, in The Cambridge Handbook of the Learning Sciences, R.K. Sawyer, Editor. 2006, Cambridge University Press: New York. p. 489-504.

58. Archer, L., et al., Doing” science versus "being” a scientist: Examining 10/11-year-old schoolchildren's constructions of science through the lens of identity. Science Education, 2010. 94(4): p. 617-639.

59. Roth, W.-M. and Y.-J. Lee, "Vygotsky's Neglected Legacy": Cultural-Historical Activity Theory. Review of Educational Research, 2007. 77(2): p. 232, 186-232, 186.

60. Roth, W.-M. and S. Lee, Science Education as/for Participation in the Community. Science Education, 2004. 88(2): p. $263-291$.

61. Gresalfi, M., et al., Constructing competence: An analysis of student participation in the activity systems of mathematics classrooms. Educational Studies in Mathematics, 2009. 70(1): p. 49-70.

62. Lachapelle, C.P., et al., Engineering is Elementary: An evaluation of years 4 through 6 field testing. 2011, Museum of Science: Boston, MA.

63. Lachapelle, C.P., et al., Engineering is Elementary: An evaluation of year 6 field testing, in NARST Annual International Conference. 2011: Orlando, FL. 